Revista de Derecho

Universidad Católica del Norte

Sección: Ensayos

Ańo 17 - No 2, 2010

pp. $185-204$

\title{
EL ESTADO DE DERECHO COMO PRINCIPIO Y SU CONSAGRACIÓN EN LA CONSTITUCIÓN POLÍTICA ${ }^{*}$
}

\section{Pablo Marshall Barberán**}

RESUMEN: Este artículo busca, en primer lugar, exponer algunas nociones sobre el concepto de Estado de Derecho y su significación teórica en la tradición europea continental. Luego, intentar hacer una conexión entre dicha tradición y la Constitución Política chilena. Para ese efecto, se intenta reconstruir las disposiciones constitucionales que han sido tradicionalmente conectadas con el concepto de Estado de Derecho, con el objetivo de lograr que el contenido de este principio constitucional, que usualmente tiene gran relevancia en el Derecho comparado, quede expresado en las disposiciones de los artículos 5, 6 y 7 de la nuestra Constitución.

PALABRAS CLAVE: Estado de Derecho - libertad individual - organización del Estado.

\section{RULE OF LAW AS A PRINCIPLE AND ITS ESTABLISHMENT IN THE Political Constitution}

ABSTRACT: This article states, firstly, some notions about the concept of Rule of Law and its theoretical meanings in the Civil Law tradition. It then attempts to connect said tradition with the Chilean Political Constitution. In order to achieve this purpose, those constitutional norms that have traditionally been related to the concept of Rule of Law are reconstructed so that the content that this constitutional principle carries, that usually has great relevance in comparative law, is expressed in articles 5, 6 and 7 of our Constitution.

Una versión preliminar y parcial de este trabajo fue presentado como ponencia en las Jornadas de Derecho Público bajo el título "Notas sobre el Estado de Derecho y su consagración en la Constitución Política". Este trabajo forma parte de una investigación financiada por la Dirección de Investigación y Desarrollo de la Universidad Austral de Chile, denominada Elaboración dogmática de los principios constitucionales de organización del Estado (2009-10).

** Profesor de Derecho Constitucional, Universidad Austral de Chile. Licenciado en Ciencias Jurídicas y Sociales, Universidad de Chile. Correo electrónico: pmarshall@uach.cl

Fecha de recepción: 7 de octubre de 2010.

Fecha de aceptación: 15 de noviembre de 2010. 
KEY WORDS: Rule of Law - individual liberty - organization of the State.

\section{1) IDEAS GENERALES}

Si bien el concepto es en sí mismo ambiguo, el Estado de Derecho se caracteriza "en general por una cierta incomodidad de cara al fenómeno

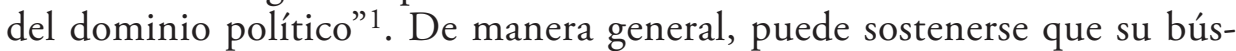
queda va dirigida a limitar y restringir el poder del Estado en favor de la libertad de los individuos.

Una primera aproximación conceptual permite entender al Estado de Derecho como un Estado donde se respeta sin condiciones el Derecho vigente: "el Derecho objetivo vigente y los derechos subjetivos que existan" 2 . En ese sentido, es un Estado sin un soberano presente que pueda suspender el Derecho a su voluntad. Estado de Derecho es condición, por tanto, de seguridad jurídica y mantenimiento del statu quo ${ }^{3}$.

Una segunda aproximación permite entender al Estado de Derecho como contraposición al estado de fuerza (o de fuerza política) ${ }^{4}$. En este sentido, la afirmación de que el Derecho debe primar sobre la política es la afirmación central de la teoría del Estado de Derecho. En este sentido, es un postulado que presenta una expectativa de normalidad, cuyo contenido puede quedar reducido a la afirmación de que el Estado debe buscar la conformación de un equilibrio que evite la excepción como estado de cosas totalmente político. Una vez que la excepción está configurada, el Estado de Derecho no tiene ningún rol que jugar, en la Revolución o el Golpe de Estado, en los momentos en que el soberano suspende el Derecho, el Estado de Derecho no puede pretender afirmar la primacía del Derecho sobre la política5.

Una tercera y última nota distintiva del Estado de Derecho, puede resumirse en que este concepto, si bien comparte supuestos institucionales con otros principios constitucionales, obedece a una lógica propia y busca la satisfacción de objetivos distintos a, por ejemplo, el principio de la democracia. La ley y los derechos fundamentales de participación son

Böckenförde, Ernst Wolfgang (2002). Estudios sobre Estado de Derecho y la Democracia, Madrid: Trotta, p. 44.

Schмiтt, Carl (1983). Teoría de la Constitución (Madrid: Alianza), p. 141.

Sobre la cuestión de la soberanía y la suspensión del Derecho vigente, puede consultarse Marshall, Pablo (2010). "La soberanía popular como fundamento del orden estatal y como principio constitucional" en Revista de Derecho de la Universidad Católica de Valparaíso, No 35 .

SCHMitT (1983) 141.

Legaz y Lacambra, Luis (1951). "El Estado de Derecho" en Revista de Administración Pública, No 6, pp. 15 y ss. 
asumidos como instituciones que reciben justificación tanto de la democracia como del Estado de Derecho, sin embargo, la reciben por razones diversas. Para la primera son canal y soporte de la expresión de la voluntad popular, para la segunda son formas de limitación de la arbitrariedad del Estado mediante un procedimiento público de formación del Derecho y de la garantía de la autonomía individual, en uno y otro caso.

Valga en el tratamiento del principio del Estado de Derecho una prevención. El principio constitucional del Estado de Derecho como un principio prescriptivo o normativo, debe distinguirse de los modelos de Estado que pueden ser descritos como Estados de Derecho. En este sentido, el primer modelo y el origen terminológico del concepto sugieren la posibilidad de entender al Estado de Derecho como un tipo de Estado. Sin embargo, la desambiguación del concepto como un concepto normativo, vienen con su consagración positiva (ya sea expresa, por ejemplo, en la Constitución española [art. 1.1] o implícita, por ejemplo, en la Ley Fundamental de Bonn [arts. 20.3 y 28.1]). En este sentido es pertinente hablar de constituciones que reconocen el principio del Estado de Derecho y de la afectación del Estado de Derecho por un acontecimiento político. En lo que sigue, se intentará limitar la exposición al Estado de Derecho como principio constitucional.

\section{2) El ESTADO DE DERECHO COMO PRINCIPIO DE LEGITIMIDAD DEL ESTADO}

\section{1) EL FUNDAMENTO}

La configuración del Estado de Derecho como modelo institucional debe distinguirse de su fundamento y su objetivo. En particular, una adecuada descripción del Estado de Derecho no puede limitarse a exponer la técnica seguida para la consecución del fin, sino que debe explicar cómo dicha técnica, por ejemplo la vinculación de la Administración a la ley, permite asegurar el objetivo de, por ejemplo, proteger la autonomía individual $^{6}$.

El fundamento del Estado de Derecho se encuentra en la doctrina del Derecho natural racional. El Estado de Derecho es, en esos términos, la organización y la actuación del Estado conforme al Derecho natural. La explicación del término, no debe entenderse, en su origen, como la sujeción del Estado al Derecho estatal, sino al Derecho suprapositivo, permanente y universal que emana de la razón. Así, su fundamento se enEntrena, Rafael (1960). "Notas sobre el concepto y clases del Estado de Derecho" en Re-
vista de Administración Pública, No 33, pp. 34-5. 
cuentra en la naturaleza del individuo: en la libertad y la igualdad de las personas que se reúnen en una comunidad y que se desarrollan en la autonomía moral, la igualdad jurídica y la posibilidad de lograr el bienestar económico a través de la adquisición de la propiedad y el ejercicio libre de la empresa.

El Estado de Derecho plantea así, un criterio de legitimidad para el dominio del Estado, en la garantía de la libertad y la propiedad de los individuos, lo que lleva a que:

[1]a sustancia de la existencia humana se desplaza desde el ámbito de lo público y de lo general al ámbito de lo privado, y es a este ámbito privado al que está referido de modo funcional lo público ${ }^{7}$.

Así, el Derecho natural racional se conforma con ser un criterio de legitimidad que se presenta como una exigencia de libertad negativa, esto es, de libertad de acción y ausencia de coacción arbitraria; no de libertad positiva, esto es, de autodeterminación y ausencia de dominio (como la democracia) ${ }^{8}$.

La versión más influyente de esta fundamentación, dentro de la tradición jurídica continental es la de Kant, quien considera que para la constitución de un Estado según los principios de la razón es necesario el respeto de ciertos principios, a saber:

(i) la libertad humana, que Kant expresa mediante la fórmula:

Nadie me puede obligar a ser feliz a su modo, sino que es lícito a cada uno buscar su felicidad por el camino que mejor le parezca, siempre y cuando no cause perjuicio a la libertad de los demás para pretender un fin semejante, libertad que puede coexistir con la libertad de todos según una posible ley universal ${ }^{9}$.

(ii) la igualdad jurídica, que puede formularse así:

Cada miembro de la comunidad tiene derechos de coacción frente a cualquier otro (...). Por todo cuanto en un Estado se halle bajo leyes de coacción lo mismo que todos los demás miembros de la comunidad (...). A cada miembro de la comunidad le ha de ser lícito alcanzar dentro de ella una posición de cualquier nivel hasta el que puedan llevarle su talento, su aplicación y su suerte. Y no es lícito

BÖCKENFÖRDE (2002) 22.

Petтiт, Philip (2004). "Liberalismo y Republicanismo" en Ovejero, Felix (ed.): Nuevas Ideas Republicanas, Barcelona: Paidós, pp. 115-35.

9 Kant, Immanuel (2004). "Teoría y Práctica" en él mismo: ¿Qué es la Ilustración?, Madrid: Alianza, p. 206. 
que los cosúbditos le cierren el paso merced a una prerrogativa hereditaria, manteniéndole eternamente, a él y su descendencia, en una posición inferior ${ }^{10}$.

(iii) Finalmente, Kant propone la idea de autolegislación pública:

(...) una ley pública, que determina para todos lo que les debe estar jurídicamente permitido o prohibido, es un acto de una voluntad pública, de la cual precede todo Derecho, y por tanto, no ha de cometer injusticia contra nadie. Mas, a este respecto, tal voluntad no puede ser sino la voluntad del pueblo entero (ya que todos deciden sobre todos y cada uno sobre sí mismo), pues solo contra si mismo/ nadie puede cometer injusticia, mientras que, tratándose de otro distinto de uno mismo, la mera voluntad de este no puede decidir sobre uno mismo nada que pudiera ser justo ${ }^{11}$.

Si bien es en su origen que la idea de Estado de Derecho se vincula de una manera especialmente estrecha con la idea de Derecho natural, con posterioridad a la Segunda Guerra Mundial y la caída de los regímenes socialistas, en particular en Alemania, el argumento del Derecho natural ha revivido en la forma de un Derecho de rango superior, frente al cual el Derecho estatal tiene que ceder ${ }^{12}$. En términos del Tribunal Constitucional Federal alemán "unos principios indispensables para la convivencia humana [...] que pertenecen a aquella base o ámbito nuclear inviolables como existe en la conciencia jurídica de todos los pueblos civilizados [...] independiente de cualquier reconocimiento estatal"13. Si bien esta discusión es interesante, no es lo que preocupa medularmente al Estado de Derecho como un principio de legitimidad de la organización del Estado ${ }^{14}$.

10 Kant (2004) 208-9.

11 Kant (2004) 213-4.

12 El argumento puede condensarse en la fórmula de Radbruch: "El conflicto entre la justicia y la seguridad jurídica podría haberse solucionado considerando que el Derecho positivo, asegurado por medio de las reglamentaciones y el poder, tiene también la primacía si es materialmente injusto e inadecuado, a no ser que la contradicción de la ley positiva con la justicia alcance una medida tan insoportable que la ley como "Derecho injusto tenga que ceder ante la justicia [...] donde ni siquiera se ha aspirado a la justicia, donde conscientemente se ha negado la igualdad, que integra el núcleo de la justicia, en la determinación del Derecho positivo, allí la ley no es simplemente algo como Derecho injusto, más bien carece totalmente de la naturaleza del Derecho". Citado en Hassemer, Winfried (2003). "Derecho Natural en el Derecho Constitucional” en Anuario Iberoamericano de Justicia Constitucional, No 7, p. 288.

13 Citado en Hassemer (2003) 286.

14 Sobre esta formulación, puede consultarse en particular Hassemer (2003) y Alexy, Robert (2000). "Derecho injusto, retroactividad y principio de legalidad penal: La doctrina del Tribunal Constitucional Federal alemán sobre los homicidios cometidos por los centinelas del muro de Berlín” en Doxa: Cuadernos de Filosofía del Derecho, No 23, pp. 197-232. 


\section{2) El Estado De DERECHO y la DEMOCRACIA}

Detrás del Estado de Derecho como principio de legitimidad está la filosofía política liberal, que comprende que la legitimidad del Estado se justifica de una manera distinta de como la pretende justificar la filosofía política democrática, que encuentra su propio principio de legitimación en la teoría de la soberanía del pueblo y la democracia como forma de gobierno.

El Estado de Derecho y la democracia si bien tienen rasgos comunes, muchas veces tienden a oponerse y a exigir soluciones diversas en un mismo asunto. La democracia responde a la pregunta sobre quién es el titular del poder estatal. El Estado de Derecho, por otro lado, responde a la pregunta sobre el contenido de la actuación estatal. De esta forma, la democracia es posible sin el Estado de Derecho y el Estado de Derecho es posible en regímenes que no son democráticos.

El Estado está legitimado, desde el punto de vista del liberalismo, cuando no interfiere en la esfera del individuo. A continuación, la esfera del individuo se puede determinar como el conjunto de libertades que posibilitan la realización del plan de vida que autónomamente el individuo se ha trazado y para el cual no requiere la ayuda de los demás. Así, el liberalismo exige que el Estado maximice el grado de libertad que los individuos tienen. Sin embargo, la forma en que el Estado cumple dicho objetivo es, en principio, irrelevante. Así, la conformación de un régimen democrático, estará justificada para el liberalismo, si es que este régimen tiende a garantizar la libertad individual.

En términos generales, la democracia tiende a garantizar la libertad individual. Esta afirmación es especialmente relevante cuando se compara a un régimen democrático con una monarquía autoritaria. Sin embargo, la democracia muchas veces afecta la libertad individual con la finalidad de satisfacer otros objetivos, como, por ejemplo, propiciar una mayor igualdad. A su vez, una monarquía autocrática puede tener un monarca ilustrado y liberal a la cabeza y respetar las libertades de sus súbditos de una manera más estricta que la misma democracia. En ese escenario, el liberalismo es agnóstico a la forma de gobierno, mientras el criterio de legitimidad basado en la libertad individual sea satisfecho. Preferirá una monarquía liberal a una democracia radical. Con todo, no es posible afirmar seriamente que el Estado de Derecho no está ligado a la democracia, en la medida que la democracia será siempre uno de los controles fundamentales frente al poder arbitrario del Estado. La democracia protege de mejor manera que la monarquía la libertad del individuo porque son los propios destinatarios del poder del Estado quienes ejercerán de manera relevante dicho poder.

La vigencia paralela del Estado de Derecho y la democracia se justifica, como una forma de reconocer límites a lo que el pueblo en la demo- 
cracia puede decidir, que vienen dados por los derechos fundamentales que incluso los representantes del pueblo deben respetar ${ }^{15}$. En ello existe, desde las más diversas teorías sobre la legitimidad del Estado, acuerdo. Sin embargo, está abierta la discusión sobre la forma o el método en que dichos derechos deben ser protegidos frente a la afectación arbitraria, ya no del monarca, sino del legislador democrático.

\section{3) ORIGEN Y EVOLUCIÓN DEL CONCEPTO DEL ESTADO DE DERECHO}

El origen del concepto de Estado de Derecho es un concepto propio del Derecho constitucional alemán y debe su denominación a Robert von Mohl. No tiene un correlato exacto en Francia ni en los países anglosajones. Sí ha tenido gran influencia en España y por esa vía en el Derecho constitucional chileno contemporáneo, en el que no ha recibido, como en aquellos Estados, consagración constitucional.

\section{1) El ORIGEN DEL Estado De DERECHO}

En su origen, la idea del Estado de Derecho hace referencia al carácter racional de la organización del Estado, en armonía con lo dispuesto por los teóricos del Derecho natural liberal. Sobre esta base, Böckenförde, sienta las características originales del Estado de Derecho de la siguiente manera:

(a) el Estado es una creación de la comunidad política y está a su servicio, no es una creación de, ni está encomendado a, ningún orden superior o divino;

(b) los objetivos del Estado quedan restringidos a la garantía de la libertad, la seguridad y la propiedad de los individuos; y

(c) la organización y regulación de la actividad del Estado debe realizarse de acuerdo a principios racionales, incluyendo entre estos los siguientes: el reconocimiento de los derechos básicos de la ciudadanía (libertad, igualdad y propiedad), la independencia de los jueces, la responsabilidad del gobierno, el dominio de la ley, la representación del pueblo y la separación de funciones ${ }^{16}$.

Todas estas ideas sugieren que la idea del Estado de Derecho es la concreción institucional de las ideas de la filosofía política liberal racional, pre-

\footnotetext{
15 Benda, E. / Maihofer, W. / Vogel, J. /Hesse, K. / Heyde, W. (1996). Manual de Derecho Constitucional, Madrid: Marcial Pons, p. 490.

16 BÖCKENFÖRDE (2002) 20.
} 
sentándose como una opción para la organización y actuación del Estado tanto frente a la tentación del despotismo absolutista como frente al ejercicio del poder político democrático ${ }^{17}$. El Estado de Derecho en su origen puede ser entonces caracterizado como un Estado de Derecho burgués.

El lugar que tiene la institución de la ley para el Estado de Derecho es central para afirmar la primacía del individuo frente al Estado y va a ser el eje de continuidad sobre el cual el concepto de Estado de Derecho se va a desarrollar. En la formulación de Böckenförde:

La ley es una regla general que surge con el asentimiento de la representación del pueblo en un procedimiento caracterizado por la discusión y la publicidad. Todos los principios esenciales para el Estado de Derecho están incluidos institucionalmente en este concepto de ley, y en él reciben su forma. El sentimiento de la representación del pueblo garantiza el principio de la libertad y la posición del sujeto del ciudadano; la generalidad de la ley impide ingerencias en el ámbito de la libertad civil [...]; el procedimiento determinado por la discusión y la publicidad garantiza la medida de racionalidad que el contenido de la ley puede humanamente alcanzar ${ }^{18}$.

La ley, en esos términos, se convierte en la garantía de los individuos frente al poder del Estado.

\section{2) ESTADO DE DERECHO FORMAL Y ESTADO DE DERECHO MATERIAL}

La tendencia posterior a la conformación original del Estado de Derecho en Alemania fue su reducción a un concepto formal. Así, se habla hasta hoy de un concepto formal de Estado de Derecho o de un Estado de Derecho formal. Puede caracterizarse a este de la siguiente manera:

(a) el Estado de Derecho no está vinculado a determinada filosofía política, debe ser algo "apolítico", por lo tanto, se debe vaciar el contenido liberal;

(b) el Estado de Derecho exige imperio de las leyes, esto es, sumisión de las autoridades al Derecho y en especial sumisión de la Administración a la ley; y

(c) exige la protección judicial del individuo frente a la Administración.

17 Así, el Estado de Derecho no es necesariamente un principio de inspiración democrático: "la libertad política de los ciudadanos [...] vale como culminación y garantía de la libertad civil, pero encuentra su límite allí donde no llega la protección de la libertad civil, donde esta se pone en peligro o, en otras palabras, donde deja de dar preferencia a la razón [...]". BÖCKENFÖRDE (2002) 23.

18 BÖCKENFÖRDE (2002) 23. 
La formulación más extrema del Estado de Derecho formal procede de los teóricos del positivismo que lo presentan como una determinada relación de orden entre la ley, la Administración y los individuos, llegando a reducirse a la mera legalidad de la Administración: "la Administración no puede intervenir en la esfera de la libertad del individuo, ni en contra de una ley (contra legem), ni sin una base legal (praeter o ultra legem)" 19 .

Así, se rechaza cualquier cuestionamiento liberal de la libertad de configuración del orden jurídico por parte del legislador. Esta evolución del concepto de Estado de Derecho no es más que la contrapartida de la reducción del concepto material de ley, que se erigía como eje del concepto original del Estado de Derecho, a un concepto formal de ley ${ }^{20}$.

Esta reducción, sin embargo, no transforma al concepto de Estado de Derecho en algo vacuo, dicho concepto sigue conformando y manteniendo, ahora de una manera meramente formal, el statu quo que el liberalismo había establecido como centro de gravedad del concepto de Estado de Derecho, esto es, libertad, seguridad y propiedad.

La crisis social que produjo un conflicto de legitimidad del Estado liberal a comienzos del siglo XX, se dirigió particularmente contra el concepto de Estado de Derecho como un estorbo para el cambio social necesario para la vuelta de la legitimidad al Estado. Con ello, surgen nuevas concepciones del Estado de Derecho que "reflejan nuevas ideas de justicia” política. Ellas proponen sustituir la noción decimonónica del Estado de Derecho formal por un Estado de Derecho material, que dé cuenta de los aspectos sociales urgentes de la comunidad. La igual libertad formal asegurada por el Estado de Derecho ya no es suficiente, y el pueblo reclama una igual libertad real.

Una segunda explicación, enfatiza el rol fundamental que cumplieron los hechos sucedidos en Alemania entre 1933 y 1945 en la desconfianza que genera confiar la protección de los derechos más esenciales a mecanismos institucionales que cedieron fácilmente ante la excepción política acaecida en ese país. La respuesta del Estado de Derecho material es también una respuesta a la pregunta de cuál es la mejor forma de proteger los derechos fundamentales frente a la excepcionalidad política ${ }^{21}$.

La reacción crítica contra el déficit de legitimidad que el Estado de Derecho presentaba, fue seguida de la reformulación del concepto tradicional, dirigiéndolo ya no solo a la delimitación y defensa de la libertad

19 Anschütz, citado en BöcKenförde (2002) 29. Sobre los teóricos del Estado de Derecho formal puede consultarse Von Hippel, Ernst (1956). "El concepto de la teoría general del Estado y el problema del Estado de Derecho" en Revista de Estudios Politicos, № 90.

20 De Otтo, Ignacio (1988): Derecho Constitucional. Sistema de Fuentes (Barcelona, Ed. Ariel), pp. 162-80.

21 Benda (1996), pp. 489-90. 
individual, sino también a la realización de tareas y la persecución de objetivos por parte del Estado 22 .

La fórmula propuesta por los teóricos del Estado de Derecho material se dirige en particular contra la concepción tradicional de los derechos fundamentales. Los derechos como protección de la libertad individual frente al Estado, orientando la organización y el funcionamiento de este, de manera de cautelar la no intervención, son reemplazados por unos derechos que aparecen como bienes o valores cuya función no es ya solo limitar la acción del Estado sino dirigir dicha actuación a la realización de determinados objetivos, esto es, hacia la realización de los valores o bienes establecidos como derechos, que son concebidos como parámetros de justicia material.

Así, toda la acción del Estado queda dirigida ya por la decisión fundamental sobre el orden de cosas que debe imperar en el Estado de Derecho. No queda mayor margen de acción para la toma de decisiones estatales, más que la realización de los derechos fundamentales, que ya no son entendidos como límites a la esfera de acción del Estado sino que son entendidos como un "orden objetivo de valores" que el Estado debe reali$\operatorname{zar}^{23}$.

Una concepción del Estado de Derecho material equilibrada, para Benda, por ejemplo, involucra "que el poder estatal es considerado como vinculado sobre todo a determinados principios y valores jurídicos superiores". Para que esos principios puedan imponerse "deben disponer de un rango superior al de las decisiones de la mayoría parlamentaria de turno". El Estado de Derecho material exige la supremacía de la Constitución. Sin embargo, la democracia "se ahogaría si las decisiones constitucionales adoptadas no dejaran margen suficiente de configuración a la política”. De ahí la necesidad de cierto equilibrio:

Determinados principios deben ser respetados porque parecen irrenunciables, pero el debate político debe discurrir permitiendo tener en cuenta el cambio de las circunstancias y de las ideas. El debate político en libertad debe poder decidirse entre alternativas ${ }^{24}$.

Dichos principios irrenunciables son los derechos y principios fundamentales consagrados en la Constitución, cuya vigencia jurídica no puede quedar encomendada a un órgano político, sino que debe quedar entregada a un tribunal.

BÖCKENFÖRDE (2002), p. 32.

BÖCKENFÖRDE (2002), pp. 40-1.

BENDA (1996), pp. 490-1 
La Constitución como orden objetivo de valores parece decidir demasiado. Este orden, por lo menos, genera una relación de tensión con el propio núcleo fundamental del concepto de Estado de Derecho y con el principio de la democracia. En relación con el primero, la tensión se relaciona con el lugar de la libertad que el concepto formal de Estado de Derecho pretendía asegurar en forma categórica. La nueva formulación pasa por alto el contenido material de las garantías formales del Estado de Derecho y con ello genera una tensión irresoluble con la delimitación y garantía de la libertad individual que estaba en la base del origen y desarrollo del concepto. Ello es así, en la medida que

[s] i se dota a los postulados ético-morales o a los valores materiales una vinculatividad jurídica que va más allá de la garantía de la libertad igual de todos y de las exigencias fundamentales de la vida en común ordenada, se llega inevitablemente a una socialización de la libertad y de la autonomía individuales. Estas quedan sometidas al dominio de los que ejercen el monopolio de la interpretación de estos postulados o valores, o que se los apropian [...] ¿No se abre entonces la puerta al totalitarismo constitucional? ¿Qué clase de seguridad en sí mismo tiene un pueblo que se cree obligado a fijar como intangibles, con la coacción del Derecho, los llamados valores fundamentales de la regulación de la vida y de su organización política, tanto para sí mismo como para las generaciones futuras, a las que con ello está negándoles desde el principio el reconocimiento de su propia madurez? [...] ¿en qué medida nos encontramos entonces aún ante una regulación de la libertad propia de un Estado de Derecho? ${ }^{25}$.

Una comprensión equilibrada del Estado de Derecho que no se entrometa de una manera inaceptable en la toma de las decisiones democráticas, pero que al mismo tiempo no se restrinja a establecer mecanismos institucionales que aparezcan como estériles frente a las exigencias de justicia material vertidas en el catálogo de derechos fundamentales, necesariamente tiene que tomar en cuenta tanto el objetivo principal del Estado de Derecho como su rol en un régimen democrático. En este sentido, la amenaza para la libertad individual y para el gobierno democrático que se erige en la concepción material-objetiva de la Constitución, de los derechos fundamentales y del Estado de Derecho, aparece como un argumento a favor de volver a una concepción formal (o relativamente formal) del Estado de Derecho.

25 BöCKENFÖRDE, 2002, pp. 42-3 
Que los derechos fundamentales y otros valores constitucionales se erijan como objetivos a ser realizados, hacen que estos entren en competencia con las decisiones del pueblo en la función de guiar la actuación estatal. Al mismo tiempo que los derechos invaden la esfera pública que normalmente corresponde a la deliberación democrática, también tienden a invadir en la esfera privada. En la medida que los derechos fundamentales se transforman de libertades en valores, se vuelven pertinentes como razones de intervención estatal en áreas tradicionalmente entregadas a la autonomía de los ciudadanos.

Un ejemplo llamativo sobre esta cuestión es la utilización de la decisión constitucional a favor del valor de la vida, establecida, sin embargo, solo con el carácter de un mandato de protección al legislador (art. $19 \mathrm{n}^{\circ}$ 1 inc. $\left.2^{\circ} \mathrm{CPol}\right)$, para justificar la intromisión estatal en la libertad de la mujer que quiere evitar un embarazo, mediante la prohibición de los mecanismos de anticoncepción de emergencia. La solución del asunto de "La píldora del día después", solo puede ser justificado apelando a un Estado de Derecho material, aunque ello no sirve para justificar la errónea interpretación de las disposiciones constitucionales y el fallo contra legem del Tribunal Constitucional ${ }^{26}$.

\section{4) El Contenido del Estado de DeRecho}

De la idea del Estado de Derecho como un principio constitucional liberal pueden concluirse dos principios que están contenidos en todas las formulaciones del Estado de Derecho. Ellos son, en la célebre formulación de Carl Schmitt -paradójicamente uno de los principales críticos del parlamentarismo liberal- el principio de distribución y el principio de organización.

Por supuesto que con el tiempo, y con la elaboración doctrinal y jurisprudencial, dicho contenido ha tendido a sofisticarse.

Por ejemplo, Legaz consideraba que el Estado de Derecho responde a una concepción personalista de la justicia, para cuyo servicio se requiere: (i) la afirmación de que el ordenamiento jurídico constituye un todo jerárquicamente estructurado, al que corresponde una primacía de la norma general de la ley; (ii) la afirmación de los derechos humanos fundamentales; (iii) la existencia de un fuero de la personalidad jurídica; (iv) un sistema de responsabilidad de la Administración y de recursos contencioso-administrativos, (v), por último, aunque no constituya una

26 STC Rol 740-08 
nota esencial, sino contingente, el Estado de Derecho tiende hacia lo que puede llamarse el control jurisdiccional de la Administración ${ }^{27}$.

Mucho más actual, Benda considera que el concepto de Estado de Derecho involucra: (i) seguridad jurídica y justicia; (ii) que la Constitución sea la norma suprema; (iii) la vinculación de los poderes públicos a la ley y al Derecho; (iv) vinculación de los poderes públicos por la primacía y reserva de ley; (v) división de poderes; (vi) protección de los derechos fundamentales; (vii) tutela judicial; (viii) protección de la confianza jurídica ${ }^{28}$.

Como puede evidenciarse, al igual como el concepto de Estado de Derecho fue evolucionando a través de la historia, las instituciones y requisitos que lo componen también han variado. Sin embargo, todos estos contenidos, son subsumibles en las ideas más simples y generales de Schmitt. El principio de la distribución presenta la separación fundamental de la filosofía liberal entre la esfera pública y la esfera privada. El principio de la organización está dirigido a institucionalizar la protección del principio de la distribución, que aparece en un comienzo como un principio falto de concreción.

\section{1) EL PRINCIPIO DE LA DISTRIBUCIÓN}

El principio de la distribución se puede definir de la siguiente manera:

La esfera de libertad del individuo se supone como un dato anterior al Estado, quedando la libertad del individuo ilimitada en principio, mientras que la facultad del Estado para invadirla es limitada en principio 29 .

La más famosa consagración constitucional del principio de la distribución es la establecida en la Declaración de los Derechos del Hombre y del Ciudadano de 1789 establecía:

Artículo 4.- La libertad consiste en poder hacer todo aquello que no perjudique a otro: por eso, el ejercicio de los derechos naturales de cada hombre no tiene otros limites que los que garantizan a los demás miembros de la sociedad el goce de estos mismos derechos. Tales límites solo pueden ser determinados por la ley.

Artículo 5.- La ley solo tiene derecho a prohibir los actos perjudiciales para la sociedad. Nada que no esté prohibido por la ley puede ser impedido, y nadie puede ser constreñido a hacer algo que esta no ordene.

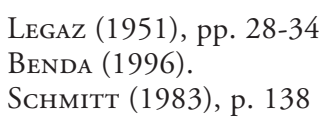


La implementación del principio de distribución es llevado a cabo por el establecimiento de los derechos fundamentales de libertad, que establecen la barrera última que el poder del Estado no puede flanquear.

\section{2) EL PRINCIPIO DE ORGANIZACIÓN}

El principio de organización es presentado por Schmitt de la siguiente manera:

Sirve para poner en la práctica el principio de distribución: el poder del Estado (limitado en principio) se divide y se encierra en un sistema de competencias circunscritas ${ }^{30}$.

Si bien Schmitt identifica el principio de organización con la separación de los poderes y la distribución de las competencias estatales entre ellos, la organización del Estado con la finalidad de implementar medidas que funcionalmente tiendan a garantizar el principio de distribución, puede entenderse más comprensivamente. Así, otras fórmulas de control del poder del Estado que se realizan mediante su organización forman parte del principio de organización ${ }^{31}$.

En primer lugar, dentro de estas formas organizativas del Estado de Derecho, sin duda se encuentra la separación de poderes y distribución de funciones entre los órganos del Estado. La división de las funciones ejecutiva, legislativa y especialmente la judicial, forma parte del núcleo indubitado del Estado de Derecho.

Esta división de poderes contiene "el principio básico de la mensurabilidad de todas las manifestaciones del poder del Estado", que se desprende del principio de distribución. De esta manera: "Todas las actividades estatales, incluso la legislación y el gobierno, se pueden reducir a un previo funcionamiento calculable, según normas fijadas de antemano"32.

Luego, como concreción de la mensurabilidad general, se encuentra el principio de legalidad. En su versión más tosca, como la simple sujeción del Estado al Derecho preestablecido. En su versión más propia, mediante la sujeción de la actuación de la Administración a la ley y la revisabilidad de tal sujeción por parte de un juez independiente ${ }^{33}$.

$\mathrm{La}$ independencia judicial, por tanto, es otra característica organizativa, que se vincula, tanto a la separación de poderes, en la que recibe su realización más relevante, como a la legalidad. Con la legalidad tiene una relación de garantía de la posición del individuo frente a la Administración, dándole eficacia a la garantía abstracta de la sujeción a la ley de

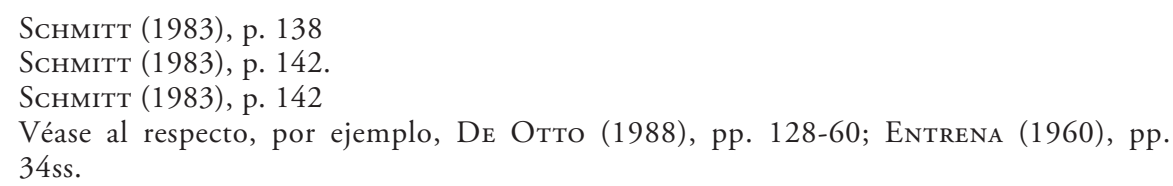


esta. La independencia judicial tiene su explicación, desde el principio del Estado de Derecho, como la forma de garantizar el control judicial de la administración ${ }^{34}$.

En relación con la legalidad en un sentido amplio, como sujeción al Derecho preestablecido, se encuentra la vinculación del legislador a la ley constitucional. Como una reproducción de la relación entre ley y acto administrativo, las normas constitucionales como normas jurídicas se presentan como una exigencia competencial, procedimental y material al ejercicio del Poder Legislativo ${ }^{35}$.

Como corolario y consecuencia de las formas organizativas básicas del Estado de Derecho, se puede observar una "conformación judicial general de toda la vida del Estado". Todos los conflictos dentro del Estado son solucionados en última instancia por un juez, que pretende solucionar los conflictos aplicando las normas preestablecidas por el orden jurídico vigente. Ello, si se mira este enunciado con algo de crítica, es imposible para varios de los supuestos de litigios constitucionales. La sujeción de la política al Derecho no es posible en todos los supuestos, en especial allí donde faltan las bases para entender que un juez soluciona el asunto aplicando el Derecho preestablecido. Ese es un problema en muchos casos de control de constitucionalidad de la ley o de otros actos de decisión política judicial ${ }^{36}$.

\section{5) El CONTENido del Estado de DeRecho en la Constitución POLÍTICA}

\section{1) El PRINCIPIO DE LA DISTRIBUCIÓN}

El artículo 5 inciso $2^{\circ}$ establece:

El ejercicio de la soberanía reconoce como limitación el respeto a los derechos esenciales que emanan de la naturaleza humana. Es deber de los órganos del Estado respetar y promover tales derechos, garantizados por esta Constitución, asi como por los tratados internacionales ratificados por Chile y que se encuentren vigentes.

Esta disposición plantea varias cuestiones interesantes.

(i) El enunciado del artículo 5 inciso $2^{\circ}$ como consagración del principio de distribución. La afirmación de que el Estado tiene un deber de respetar

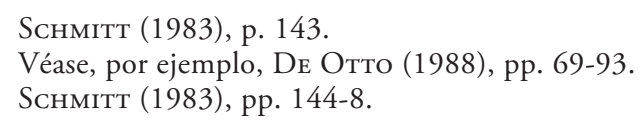


los derechos fundamentales es la afirmación central del Estado de Derecho e implementa de esa manera el principio de distribución entre lo permitido y lo no permitido para el Estado. La Constitución establece, mediante el reconocimiento del principio de la distribución, la primacía de la libertad del individuo respecto de la potestad estatal de limitar dicha libertad, la que debe realizarse mediante la dictación de normas jurídicas mediadas por un procedimiento racional de elaboración.

(ii) El Estado de Derecho material en la Constitución Política. La cuestión interesante es determinar cuál es el significado del deber de promoción que acompaña al deber de respeto de los derechos fundamentales. El deber de respeto afirma, sin lugar a dudas, la obligación de abstención de parte del Estado, de toda acción que afecte los derechos fundamentales. El deber de promoción, afirma la obligación que tiene el Estado, no solo de abstenerse, sino también de realizar acciones positivas que contribuyan a realizar dichos derechos. En este sentido el deber de promoción coincide con el imperativo de lo que más arriba se ha llamado Estado de Derecho material. La cuestión de cómo se realiza la vinculación de los poderes estatales a los derechos fundamentales, si directamente o mediada por la intervención del los órganos políticos superiores, típicamente mediante la ley, es una cuestión que dicha afirmación no puede resolver.

(iii) La garantía del principio de distribución. El principio de distribución es una exigencia de justicia material. La forma en la cual el resultado exigido por el principio de la distribución se lleva a cabo, permite diversas implementaciones. En primer lugar, está la decisión de concretar el principio de la distribución mediante un catálogo taxativo de derechos fundamentales. Esa ha sido la tendencia en el Derecho contemporáneo. En segundo lugar, está la decisión sobre cuál va a ser el rol de dicho catálogo. En la concepción del Estado de Derecho formal, el catálogo de derechos no puede tener un rol más allá del simbolismo político. La declaración de derechos es una decisión que expresa el principio de la distribución, pero que no implementa un sistema de protección o garantía directo de los derechos fundamentales en sí mismo. La protección de la esfera individual frente al poder del Estado debe ser buscada en otros arreglos institucionales, particularmente a través del principio de la organización. En la concepción del Estado de Derecho material, el catálogo de derechos tiene un rol que va más allá del simbolismo político. Los derechos fundamentales son garantizados de forma directa, típicamente mediante su protección judicial. Sin embargo, esta alternativa de garantía directa no obsta a que el principio de organización sea considerado, todavía en el Estado de Derecho material, algo necesario para la cabal protección de los derechos fundamentales.

(iv) Los derechos fundamentales en la Constitución Politica. El principio de distribución establecido en el artículo 5 inciso $2^{\circ}$ es complementado mediante una regulación pormenorizada de los derechos fun- 
damentales establecida en el artículo 19 de la Constitución Política. Allí, se garantizan los principales derechos liberales que son reconocidos en el surgimiento y la evolución del Estado de Derecho.

(v) Los derechos como limites a la soberanía. La afirmación de que los derechos esenciales que emanan de la naturaleza humana pueden limitar el poder del pueblo de decidir sobre la normalidad y la excepción, es la afirmación por parte de la Constitución de que el poder constituyente al configurar el régimen jurídico y político que se sostienen en la Constitución Política, tuvo en especial consideración la tradición liberal que considera que los derechos individuales son anteriores al Estado y que estos deben ser garantizados para que los individuos puedan perseguir la realización del propio plan de vida, por sobre la consideración de los intereses colectivos. Sin embargo, tal afirmación, en la medida que es establecida en el ejercicio del poder constituyente, no pudo en ningún sentido limitarlo. La expresión "reconoce" hace referencia a que el límite no está impuesto a la soberanía, por el contrario, es en ejercicio del poder constituyente del soberano que se reconoce esta limitación.

La consideración anterior ve reforzada su posición, luego que el inciso afirma que el Estado solo se verá obligado por esos derechos que emanan de la naturaleza humana, si estos están consagrados o garantizados en la Constitución Política o en los tratados internacionales. En ese sentido, los derechos esenciales que no estén positivados en uno de esos instrumentos no podrán obligar al Estado.

\section{2) EL PRINCIPIO DE LA ORGANIZACIÓN}

El principio de organización aparece como un sistema de arreglos institucionales que la Constitución Política presenta para la limitación del poder del Estado frente a la posible afectación de los derechos fundamentales. Estos principios tienen un carácter formal y se presentan fundamentalmente mediante dos clases de medida: la sujeción de la autoridad estatal al Derecho y la separación de las competencias estatales en órganos diferenciados. Dentro de la primera clase, puede colocarse a (1) la supremacía constitucional; y (2) la legalidad en sentido amplio, esto es, la vinculación de los órganos del Estado al Derecho. Dentro de la segunda clase, pueden colocarse a (1) la división de poderes y la independencia judicial; y (2) la distribución de competencias.

El artículo 6 establece la siguiente disposición:

Los órganos del Estado deben someter su acción a la Constitución y a las normas dictadas conforme a ella, y garantizar el orden institucional de la República.

Los preceptos de esta Constitución obligan tanto a los titulares o integrantes de dichos órganos como a toda persona, institución o grupo. 
La infracción de esta norma generará las responsabilidades y sanciones que determine la ley.

Por su parte, el artículo 7 establece:

Los órganos del Estado actúan válidamente previa investidura regular de sus integrantes, dentro de su competencia y en la forma que prescriba la ley.

Ninguna magistratura, ninguna persona ni grupo de personas pueden atribuirse, ni aun a pretexto de circunstancias extraordinarias, otra autoridad o derechos que los que expresamente se les hayan conferido en virtud de la Constitución o las leyes.

Todo acto en contravención a este artículo es nulo y originará las responsabilidades y sanciones que la ley señale.

De ella se desprenden algunos principios constitucionales que contribuyen a darle forma al Estado de Derecho en la Constitución Política: supremacía constitucional (art. 6 inc. 10), legalidad en sentido amplio (arts. 6 inc. $1^{\circ}$ y 7 inc. $1^{\circ}$ ), garantía del orden institucional (art. 6 inc. $1^{\circ}$ ), fuerza normativa de la Constitución (art. 6 inc. $2^{\circ}$ ); responsabilidad (art. 6 inc. $3^{\circ}$ y 7 inc. $3^{\circ}$ ), distribución de competencias (art. 7 incs. $1^{\circ}$ y $2^{\circ}$ ), legalidad en sentido estricto (art. $7^{\circ}$ inc. $1^{\circ}$ ).

\section{3) LA PROTECCIÓN DEL ESTADO DE DERECHO MEDIANTE LA ORGA- NIZACIÓN}

Es solo mediante un sistema de control de constitucionalidad material, que el principio de distribución surge como un arreglo institucional de protección directa de los derechos fundamentales. Hasta antes de la incorporación de los tribunales constitucionales -en Chile hasta el año 1970-, la protección del principio de distribución, esto es, de los derechos fundamentales se llevaba a cabo mediante la organización estatal propia del Estado de Derecho: separación de poderes, legislación democrática, independencia judicial y legalidad de la Administración.

No obstante que la Constitución de 1925 consagraba un catálogo de derechos fundamentales que expresaban la idea de la distribución, su garantía no quedaba entregada directamente a un juez o tribunal. Así, debe concebirse la incorporación de un tribunal constitucional como una manifestación a favor de la implementación de un mecanismo directo de control de constitucionalidad. Si bien dicha incorporación parece reflexionar sobre el fracaso de los mecanismos organizativos del Estado de Derecho con respecto a su objetivo, no puede perderse de vista la importante labor que dichos mecanismos siguen cumpliendo y cuya desatención por parte de la doctrina y los demás operadores jurídicos podría 
socavar las bases en las que se asienta el Estado de Derecho jurisdiccionalizado.

Es sobre esta base que debe tenerse en cuenta, tanto las críticas dirigidas a la adopción de una concepción material del Estado de Derecho y sus correspondientes mecanismos jurisdiccionales, como las virtudes de la tradición formalista del Estado de Derecho.

Para defender este punto de vista en nuestra realidad, se puede, junto con poner de relieve los problemas democráticos que generan las decisiones político-morales del Tribunal Constitucional contra decisiones políticas tomadas por órganos legitimados democráticamente, poner de relieve cuánto pierden los mecanismos formales del Estado de Derecho con la acción concreta del Tribunal Constitucional chileno.

Volviendo al caso de la anticoncepción de emergencia, tanto el Tribunal Constitucional como la Contraloría General de la República, han expresado, mediante sus pronunciamientos en este asunto, la necesidad de no someterse a las competencias que el Derecho constitucional y legal les ha conferido, con la finalidad superior de la protección de los derechos fundamentales. Ellos se evidencia en el caso del Tribunal Constitucional, a la hora de controlar una resolución administrativa que no tenía competencia para controlar con el argumento que su verdadera naturaleza era la de un decreto sujeto a control. En el caso de la Contraloría, por comprenderse habilitada para interpretar los fallos del Tribunal Constitucional, atribuyéndoles además un valor normativo que ni la Constitución ni ley alguna les otorga ${ }^{37}$.

Esto muestra que la consideración aislada de la supremacía constitucional o la protección de los derechos fundamentales, puede ocasionar serias heridas a nuestro sistema de mecanismos de freno de la arbitrariedad. No parece sensato fundar la acción del Tribunal Constitucional y la Contraloría de no se someterse al Derecho preestablecido con la excusa de poder someter al tal Derecho preestablecido a otros órganos estatales, más cuando esos otros órganos cuentan con una legitimidad democrática de la cual estos carecen.

Como reflexión final, debe tomarse en consideración que los mecanismos jurisdiccionales para la protección de los derechos fundamentales vienen a perfeccionar un sistema de mecanismos institucionales formales y no a reemplazarlo. Si el costo de implementarlos pasa por desestimar las formas del Derecho público que vienen informadas por una reflexión centenaria, parecen existir buenas razones para echar pie atrás en la configuración jurisdiccional de la vida estatal. Si por el contrario, pueden conciliarse $-y$ esa parece ser la dirección que hay que tomar para la discusión posterior-, la acción de la justicia constitucional deberá conformarse con ocupar un

$37 \quad$ STC 591-06 y Dictamen $N^{\circ} 31.356$, de 16 de junio de 2009. 
lugar más en el sistema de mecanismos formales, respetando la forma de organización con que la libertad individual se ha garantizado.

\section{BiBLIOGRAFÍA}

- Abendroth, Wolfgang (1973): "Sobre el concepto de Estado de Derecho democrático y social tal como se formula en la Constitución de la República Federal de Alemania”, en Sociedad Antagónica y Democracia Politica (Barcelona, Grijalbo).

- Alexy, Robert (2000): "Derecho injusto, retroactividad y principio de legalidad penal: La doctrina del Tribunal Constitucional Federal alemán sobre los homicidios cometidos por los centinelas del muro de Berlín”, en Doxa: Cuadernos de filosofía del derecho No 23, pp. 197-232

- Benda, E., W. Mainofer, J. Vogel, Konrad Hesse, y W. Heyde (1996): Manual de Derecho Constitucional (Madrid, Marcial Pons).

- Böckenförde, Ernst Wolfgang (2002): Estudios sobre Estado de Derecho y la Democracia (Madrid, Trotta).

- De Oтto, Ignacio (1988): Derecho Constitucional. Sistema de Fuentes (Barcelona, Ed. Ariel).

- Entrena, Rafael (1960) "Notas sobre el concepto y clases del Estado de Derecho", en Revista de Administración Pública No 33.

- Hassemer, Winfried (2003): "Derecho Natural en el Derecho Constitucional", en Anuario Iberoamericano de Justicia Constitucional No 7.

- Kant, Immanuel (2004): “Teoría y Práctica”, en ¿Qué es la Ilustración? (Madrid, Alianza), pp. 179-240.

- Legaz y Lacambra, Luis (1951): "El Estado de Derecho" en Revista de Administración Pública No 6.

- Marshall, Pablo (2010): "La soberanía popular como fundamento del orden estatal y como principio constitucional", en Revista de Derecho de la Universidad Católica de Valparaíso No 35.

- Pettit, Philip (2004): "Liberalismo y Republicanismo", en Ovejero, Félix (editor) Nuevas Ideas Republicanas (Barcelona, Paidós), pp. 115-35.

- Schmitt, Carl (1983): Teoría de la Constitución (Madrid: Alianza).

- Von Hippel, Ernst (1956): "El concepto de la teoría general del Estado y el problema del Estado de Derecho" en Revista de Estudios Políticos No 90. 